\title{
Prevalence, Challenges, and Interventions for Child Neglect: Cases Reported through Childline Kenya Helpline (2016-2018)
}

\author{
Sylvia Jebet Tuikong \\ Daystar University, Nairobi, Kenya \\ Email: stuikong@daystar.ac.ke
}

How to cite this paper: Tuikong, S. J. (2020). Prevalence, Challenges, and Interventions for Child Neglect: Cases Reported through Childline Kenya Helpline (2016-2018). Open Journal of Social Sciences, 8, 181-195. https://doi.org/10.4236/jss.2020.87015

Received: June 16, 2020

Accepted: July 14, 2020

Published: July 17, 2020

Copyright $\odot 2020$ by author(s) and Scientific Research Publishing Inc. This work is licensed under the Creative Commons Attribution International License (CC BY 4.0).

http://creativecommons.org/licenses/by/4.0/

\begin{abstract}
It is not easy to approximate the degree and scale of maltreatment meted against children. However, the world today is reporting a consistent increase in the number of children who are subjects of investigation or alternative response. This is a cue that the likely number of children who finally get confirmed as maltreated may be very high. Kenya particularly, is reporting an increasing rate of violence against children. This study examined the prevalence of child neglect cases reported through Childline Kenya over a period of three years, 2016 to 2018, the nature and trends of child neglect cases reported in Kenya and the interventions employed by Childline Kenya to curb child neglect. The descriptive research design was used for the study. The data were collected through Childline Kenya's helpline "116" harnessed from received phone calls from 2016 to 2018. Childline Kenya personnel received calls and recorded child neglect cases that were reported through this span of time. Interviews with Childline Kenya personnel were also conducted to complement the data reported through phone calls. Further, a desktop review of best practices of preventing and intervening for child neglect were also conducted. The collected data are presented through descriptive statistics, tables, graphs and emerging themes. The study found that, on average, there was a high prevalence of reported child neglect cases in Kenya, that there was an increase in child neglect cases reported in 2016 and 2017, with a slight drop in 2018. It also emerged that both males and females experienced child neglect, but more cases were reported among the males than females. Case management plan is the key strategy used by Childline Kenya as an intervention measure.
\end{abstract}

\section{Keywords}

Child Neglect, Prevalence, Effects, Challenges, Intervention 


\section{Introduction}

Children are valuable and are the future of every nation. Childhood days shape a person's tenets, beliefs, attitudes and abilities hence the need to secure a healthy developmental process for all children. The need to secure a smooth development trajectory is made more urgent by the fact that children across the world, in all cultures and societies go through different forms of abuse that could have grave effects in their future (Deb, 2018). It is not easy to approximate the degree and scale of maltreatment meted against children (Ruto, 2015). However, the world today is reporting a consistent increase in the number of children who are subjects of investigation or alternative response as indicated in the United States of America (USA) Administration for Children and Families Report (2018). This is a cue that the likely number of children who finally get confirmed as maltreated may be very high. Kenya particularly, is reporting an increasing rate of violence against children (Childline Kenya, 2009). Hence the need to increase child protection measures globally and in Kenya specifically.

One of the organizations that have immensely fought and supported the course of the child in Kenya is Childline Kenya. Childline Kenya has a helpline (116) where their personnel receive calls from children reporting child abuse or where the callers are seeking help for children that have been abused. Callers report or seek help for children from across the country for various forms of abuse they face including sexual and physical abuse, child abandonment and neglect, child abduction and trafficking, child labor and early marriages as well as female genital mutilation (Childline Kenya, 2009).

This paper examines child neglect cases reported through Childline Kenya over a period of three years, 2016 to 2018. The reported cases of child neglect are subdivided according to the ages of the victims of neglect in a range of $0-5,6$ 10, $11-15$ and $16-17$ years. The subsequent paragraphs discuss the child neglect cases reported in Kenya through Childline Kenya helpline service.

Child neglect is a major problem across the world; it comes with a myriad of negative effects on the neglected individual. Exposure to such abuse in childhood results in mental health problems in teenage and adulthood. A good relationship between parents and the child is vital in the child's current behavior and how they behave in the future (Gultekin \& Canturk, 2004). Neglect has no definition that is accepted across the world (Rosennman \& Rogers, 2004). However, Taner \& Gokler (2004) explain that child neglect is categorized as physical or emotional neglect. Physical neglect is the refusal or failure on the part of an adult, such as the parents or caregivers to fulfill the duty of providing food, accommodation, clothing, hygiene, play, education, safety and medical care for the child (DePanfilis \& Dubowitz, 2005). Emotional neglect refers to the non-provision of adequate emotional support, lack of attention and love, and the child being exposed to violence. Many researchers include neglect or harm caused by a lack of care on the part of parents or other caregivers as part of the definition of abuse. Conditions such as hunger and poverty are sometimes included within 
the definition of neglect. Because definitions vary and laws on reporting abuse do not always require the mandatory reporting of neglect, it is difficult to estimate the global dimensions of the problem or meaningfully to compare rates between countries. In Kenya, abandonment and neglect were the most commonly cited aspects of child abuse when adults in the community were questioned about various forms of abuse (Krug, Dahlberg, Mercy, Zwi, \& Lozano, 1996).

Emotional and physical neglect in childhood may lead to adverse effects in childhood and later in life. Moglia (2015) indicates that emotionally neglected or abused children frequently have compromised mental, social, and moral development, are usually violent, exhibit rebellious behaviors, act older than their age, are unhappy, are usually scared and upset and most of the time end up being are low achievers. In addition, these children find it hard to make friends and have impaired ability to feel and express emotions, show signs of physical neglect, and may complain of vague physical symptoms. These are major difficulties that interfere with the normal development curve in children. It is therefore essential not only to prevent emotional neglect in children but also build strong bonds and a great sense of love and belonging.

Further, Child Welfare Information Gateway (2019) illustrates that apart from the instant bodily injuries children can experience through physical neglect, a child's reaction to abuse or neglect can have lifelong and even intergenerational impacts. WHO (2020) indicates that a child who is abused is more likely to abuse others so that violence is passed on from one age group to the next. It is therefore important to prevent emotional and physical neglect to break the cycle of violence.

Recent meta-analysis of studies exploring occurrence and prevalence of neglect found that, on a global level, self-reported physical neglect was as high as $15 \%(n=60,000)$ (Stoltenborgh, Bakersman-Kraneneburg, \& Ijzendoom, 2013). Specific types of neglect within those studies found $16.3 \%$ of participants reported physical neglect and $18.4 \%$ reported emotional neglect. Other studies conducted in the US and the UK found the incidence of neglect ranges between $1.4 \%$ and $10.1 \%$ of the population (Gilbert, Wisdom, Browne, Ferguson, Webb, \& Janson, 2009). Badoe (2017) points out that child abuse is a severe and an overwhelming problem not just in Africa but across many nations. He indicates that an estimated 95 million children experience abuse annually hence the need to put in deliberate and effective child protection measures.

\section{Methodology}

The descriptive research design was employed for this study. Ringui (2012) indicates that a research design refers to a model for carrying out a study and it enables extreme control of items that may affect the validity of the research results. It is about the organization of situations and environments necessary for collecting and analyzing data in such a manner that significance to the study's 
purpose is integrated (Kothari, 2014). A descriptive research design refers to those studies that describe the characteristic features of a specific individual, a group or a situation.

The study used both quantitative and qualitative approaches. Data collected through Childline Kenya's helpline "116" harnessed from received reporting calls from 2016 to 2018. Childline Kenya personnel received calls and recorded child neglect cases that were reported through this span of time. Interviews with Childline Kenya personnel were also conducted to complement the data reported through phone calls. Further, a desktop review of best practices of preventing and intervening for child neglect was also conducted. The collected data are presented through descriptive statistics, tables, graphs and emerging themes.

\section{Results}

This section discusses the results of the study based on the following subsections:

\subsection{The Nature and Trends of Child Neglect Cases Reported in 2016}

In the year 2016, reports received through the helpline " 116 " at Childline Kenya indicate that children in various parts of the country experienced abuse in the form of child neglect. The total numbers of child neglect cases reported in 2016 were 324 . Children aged between 0 - 5 years appear to have faced child neglect the most since 110 of the 324 emerged from this age bracket. Further, child neglect cases among of 6 - 10 years were 98; 11 - 15 years were 81 whereas $16-17$ year aged was 35 . A total of 324 reported cases in a year indicate that this is a form of abuse present and is harming children hence the need to point it out and address it. The 2016 data (as shown in Table 1) clearly indicates that the abuse is worse amongst younger children compared to older children. Older children are probably in a better position to seek help, resist abuse or fend for themselves compared to the younger children.

In terms of gender, the 2016 report indicates that both girls and boys experience child neglect. A total of 158 neglect cases were reported among females whereas 166 cases among males. This depicts an almost equal measure of neglect among males and females but slightly higher among the males. Among the 0 - 5 year olds, 61 females experienced neglect compared to 49 among the males.

Table 1. Child neglect cases reported in 2016.

\begin{tabular}{cccccc}
\hline \multicolumn{7}{c}{ Age in years } \\
\hline Gender & $0-5$ & $6-10$ & $11-15$ & $16-17$ & Total \\
\hline Female & 61 & 48 & 31 & 18 & 158 \\
Male & 49 & 50 & 50 & 17 & 166 \\
Total & 110 & 98 & 81 & 35 & 324 \\
\hline
\end{tabular}


Among 6 - 10 year olds, 48 females experienced neglect compared to 50 males, 11 - 15 year olds reported that 31 females experienced neglect compared to 50 males whereas among 16 - 17 year olds, 18 females were neglected compared to 17 males as shown in Figure 1.

\subsection{The Nature and Trends of Child Neglect Cases Reported In 2017}

In 2017, child neglect cases reported through the helpline 116 in ChildLine Kenya were 382, depicting an increase in neglect cases from the previous year. The data collected indicate that in 2017, 111 cases of neglect was reported among 0 - 5 year olds, 124 among 6 - 10 year olds, 103 among 11 - 15 year olds and 44 among $16-17$ year olds as shown in Table 2. The highest cases are reported among 6 - 10 year olds. A similar trend seen in 2016 is replicated in 2017 as more neglect cases were reported among the younger children in comparison to older children.

In terms of gender, the 2017 data collected shows that more males experienced neglect in comparison with their female counterparts as indicated in Figure 2. The data shows that among 0 - 5 year olds, there were 63 males as compared to 48 females, for the 6 - 10 year olds, data indicated 64 males and 60 females,

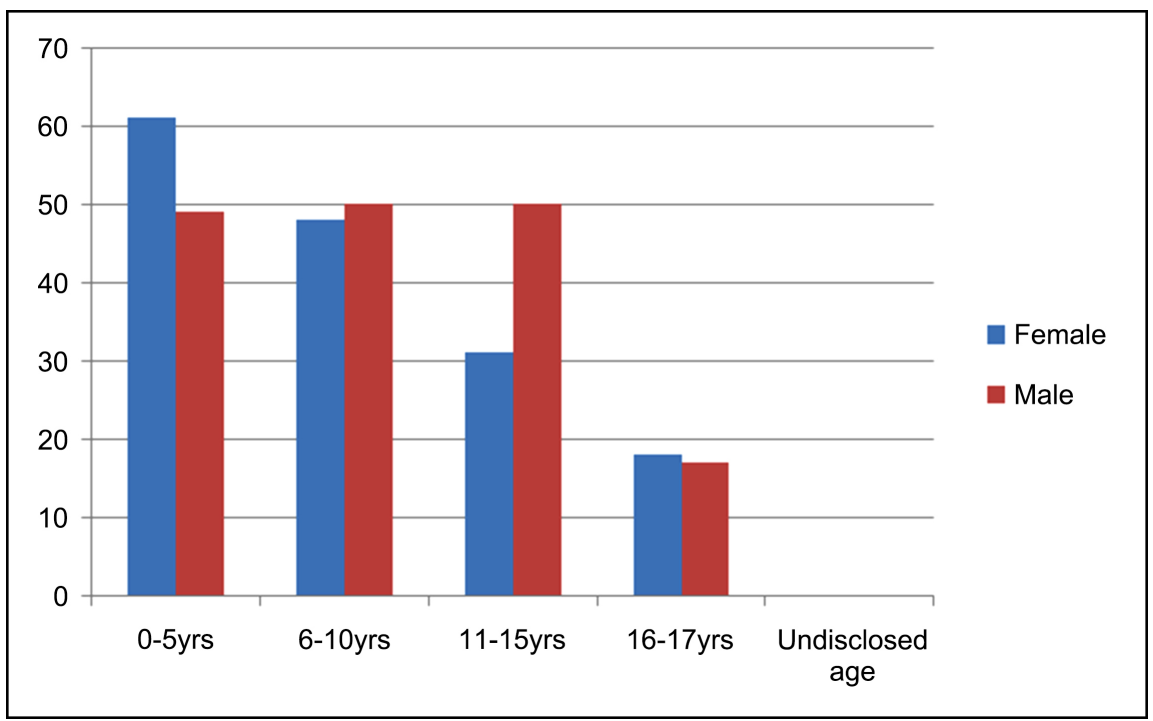

Figure 1. Child neglect cases reported in 2016 in relation to gender.

Table 2. Child neglect cases reported in 2017.

\begin{tabular}{cccccc}
\hline \multicolumn{5}{c}{ Age in years } \\
\hline Gender & $0-5$ & $6-10$ & $11-15$ & $16-17$ & Total \\
\hline Female & 48 & 60 & 51 & 19 & 178 \\
Male & 63 & 64 & 52 & 25 & 204 \\
Total & 111 & 124 & 103 & 44 & 382 \\
\hline
\end{tabular}




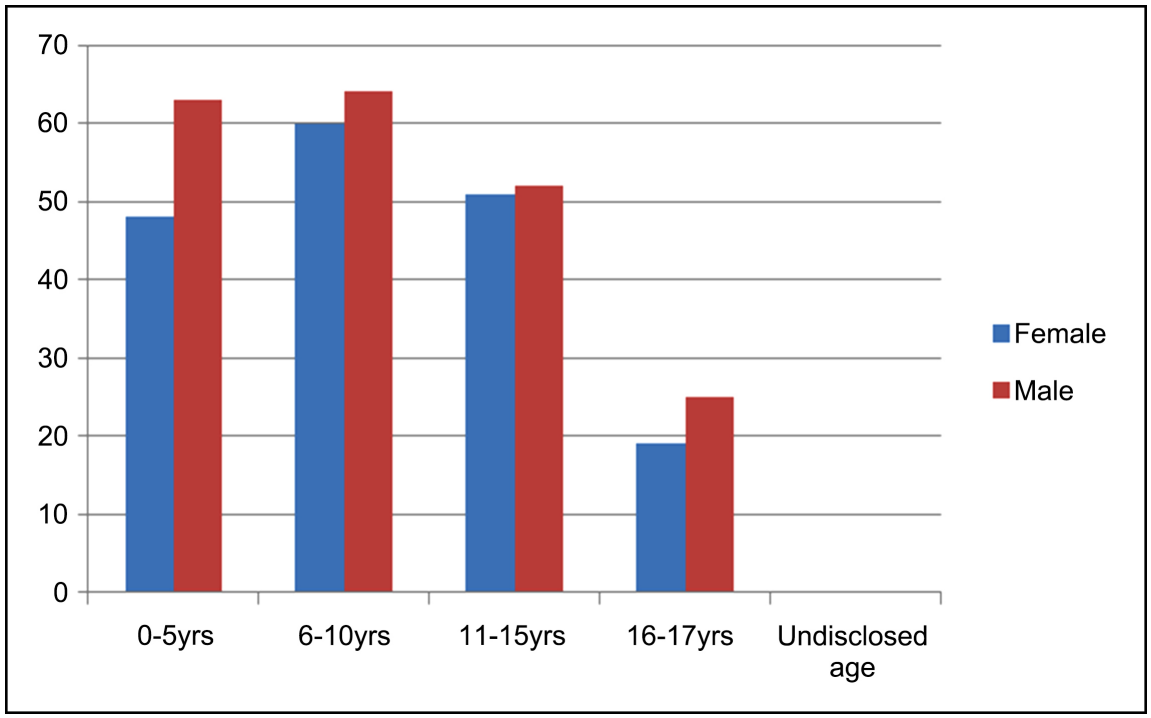

Figure 2. Child neglect cases reported in 2017 in relation gender.

11 - 15 year olds reported an almost equal number of 52 males and 51 females whereas among 16 - 17 year olds there were 25 males and 19 females. It is possible that the boys are experiencing more neglect than the girls due to cultural beliefs and practices. Most African cultures expect males to be hardy, resilient and should fend for themselves from a tender age. Unfortunately, some of these expectations turn into a form of abuse as the boys are not always able to take care of themselves.

\subsection{The Nature and Trends of Child Neglect Cases Reported In 2018}

In 2018, reported child neglect cases were 288, a significant drop from 382 cases reported in 2017. Among the 0 - 5 year olds, there were 102 cases; 6 - 10 year olds 72 cases, 11 - 15 year olds had 77 whereas 16 - 17 year olds had 37 neglect cases reported as shown in Table 3. Just like in the case of 2016 and 2017, the 2018 data shows that the younger children experience a higher rate of child neglect compared to the older children.

In terms of gender, the 2018 reported cases indicate an almost equal distribution of reported cases with males having a total of 145 cases whereas females had 143 cases. For the 0 - 5 year olds there were 54 males and 48 females, 6 - 10 year olds there were 39 males and 33 females, 11 - 15 year olds had 37 males and 40 females whereas the 16 - 17 year olds had 15 males and 22 females as indicated in Figure 3.

\subsection{Comparison of Nature and Trends of Child Neglect Cases between 2016-2018}

A comparison of the 2016, 2017 and 2018 data depict a total of 994 child neglect cases reported across all ages. These are many children going through the abuse of child neglect for a variety of reasons. The highest number of cases were 
Table 3. Child neglect cases reported in 2018.

\begin{tabular}{cccccc}
\hline \multicolumn{5}{c}{ Age in years } \\
\hline Gender & $0-5$ & $6-10$ & $11-15$ & $16-17$ & Total \\
\hline Female & 48 & 33 & 40 & 22 & 143 \\
Male & 54 & 39 & 37 & 15 & 145 \\
Total & 102 & 72 & 77 & 37 & 288 \\
\hline
\end{tabular}

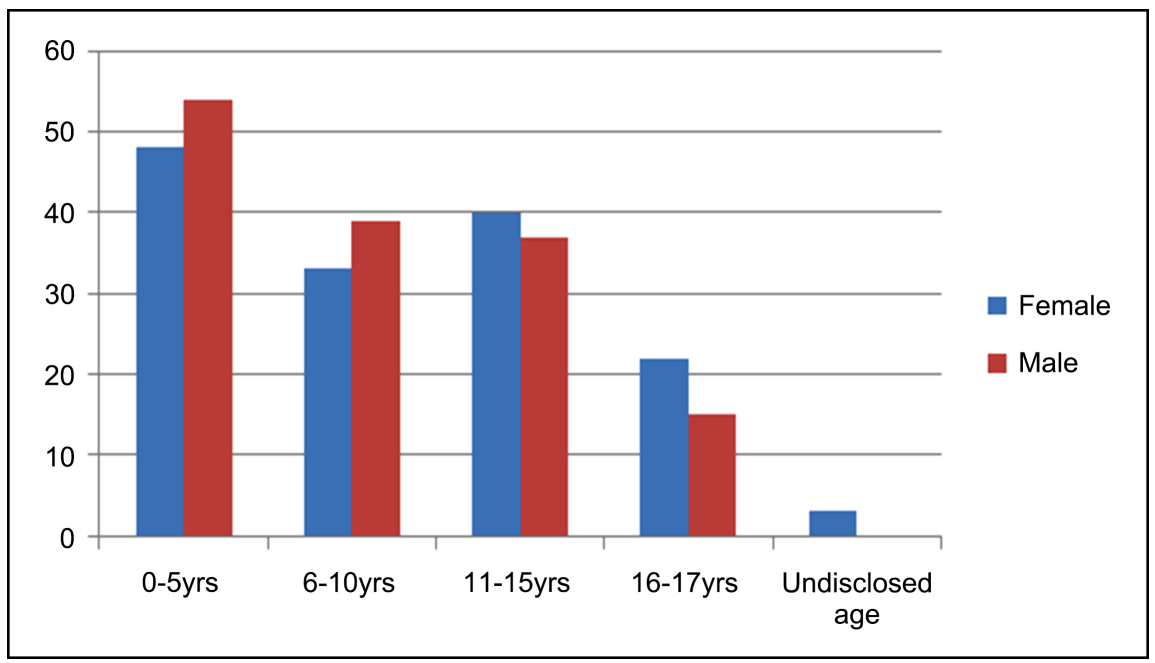

Figure 3. Child neglect cases reported in 2018 in relation to gender.

reported in 2017 (382, that is, 38.4\%), followed by 2016 with (324, that is, 32.5\%) and then 2018 (288, that is, 28.9\%) as indicated in Table 4. The 2018 data depicts a slight drop in the number of reported cases which would be attributed to either awareness campaigns that would have led to better treatment of children or a lack of reporting of cases of child neglect either due to a lack of awareness of reporting mechanisms or not being able to call due to various reasons including a lack of access to a cellphone for calling. The average of Childline Kenya reported cases across the three years is 331 hence a child neglect prevalence rate of $33 \%$.

Further, the data across the three years enhance the emerging trend that younger children experience more neglect compared to older children as exemplified in Table 4. In the three year range, the highest numbers of reported child neglect were in children aged 0 - 5 years, which is 323 cases compared to 116 amongst children aged $16-17$ years. The cases of neglect reported amongst the younger children are almost three times that of the older children hence the need to be keener in the protection of the very young children in our communities.

In terms of gender, across 2016, 2017 and 2018 there seems to be a higher trend of neglect among the males (515, that is, 51.8\%) compared to females (479, that is, $48.1 \%$ ) although the variance is small. Both males and females experience child neglect from the data collected in the three year range as de- 
picted in Figure 4.

\subsection{Child Neglect Interventional Measures Applied by Childline Kenya}

The study also sought to do an assessment of interventional measures applied by Childline Kenya counselors for victims of child abuse and child neglect as well as the challenges faced. The interview sessions were done with five of the Childline Kenya Counselors. The interview sessions brought out a detailed case management plan used by the organization in handling child abuse and neglect cases reported through the helpline service. The counselors indicated that the organization applies the standard case management design used globally to intervene for child abuse and neglect. The four major components that form the basis of case management systems promote essential and effective responses to child

Table 4. Child neglect cases reported 2016-2018.

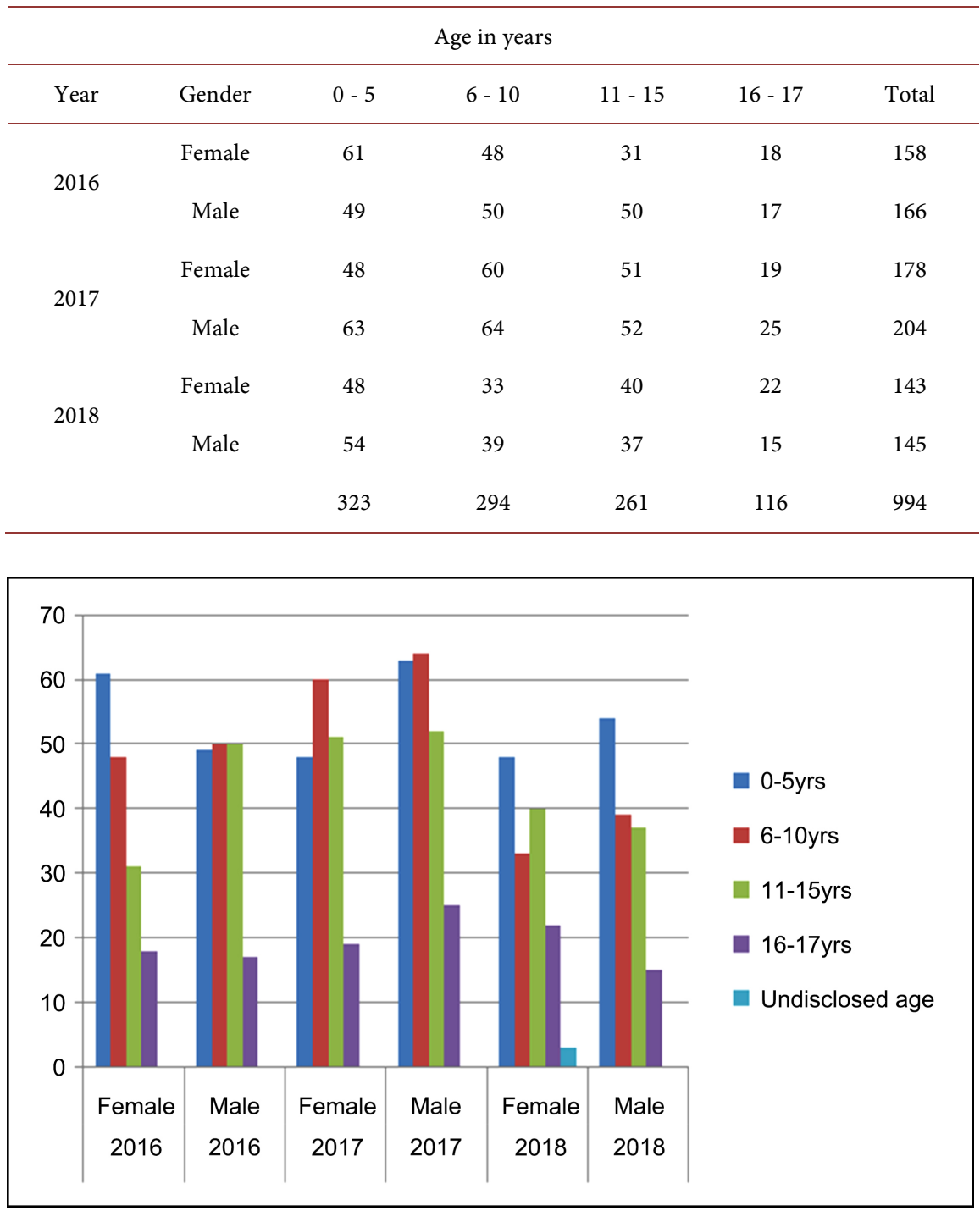

Figure 4. Comparison of child neglect cases in relation to gender 2016-2018. 
protection to ensure child safety. The components used include identification and assessment of the child abuse and neglect case reported, individual support planning, referral and liaison services when required and monitoring and review including case closure.

The counselors indicated that one of the components include identification and assessment (opening of a case and start of documentation) of child abuse and neglect cases. The counselors indicated that there are several methods of identifying children going through or that are susceptible to any risks that need attention through case management. The counselors, during the interview, indicated that for Childline Kenya, most of the cases are registered through the helpline. They explained that within any type of well-developed and functioning child protection system there are mechanisms for referral between agencies.

The interview sessions also revealed that other aspects that Childline Kenya does include setting up formal referral mechanisms, establishment of taskforces and working groups that are useful in in evaluating the current referral systems to identify and address any problems/gaps. The interview revealed that after identification and assessment, an individual support planning (planning of response and care) is done for each case of abuse. The counselors indicated that individual support plan they draw for each case of abuse usually depended on the circumstances of the child and their caregivers as well as their environment, the plan always indicated what services are required to meet the child's immediate and long-term needs. The plan developed addresses each case of child abuse and is always based on the best interests of the child, and developed with the participation of the child, their caregivers and other relevant stakeholders.

The interview revealed that for the support plan to be effective, the Children's Officer on the ground where the case has been reported should be allocated to the case as the case worker. This Children officer carries out further assessment/ social inquiry to determine needs of the child and address the issues. The plan must include details of verification of the information provided at the time of the call, the precise assistance that will be provided to the child and their family, where this assistance is to take place, who is responsible for providing it and the length of time for which it is to be provided.

Further, the interview revealed that, another component forming the case management system addressing child abuse and neglect cases is referral and liaison with support services where required. The interview showed that referral is the process of facilitating the client's utilization of available support systems to meet needs identified. The counselors emphasized the referral component was based the support services that the child required which may include referral to education services, health services, legal or livelihood support among others.

The counselors, through the interview explained that the majority of reported cases the helpline relies on for the referral services are from other providers, hence a need to establish a formalized referral mechanism indicating the roles and responsibilities of the participating agencies, including which agency/authori- 
ties is responsible for providing which service to whom and where. It should also indicate how the referrals should be conducted (the referral pathway). The goal of interagency case management is to connect agencies to one another to provide additional services to clients. The interview session with the Childline Kenya Counselors indicated that the organization had informal agreements with the referral partners which made it easy and faster to refer a child.

The interview findings also revealed that another component that guides case management system in Childline Kenya is monitoring and review (including case closure). It was revealed that case conferences are held and are an important and necessary part of case management. Their main purpose is to systematically and thoroughly plan and monitor the assistance given to a child and the progress of this assistance to ensure there is a successful outcome.

The interview also revealed that other interventions used by Childline Kenya other than the helpline includes training of children as peer educators in matters of reproductive health, providing factual information to the clients accessing the line to help them make informed decisions, providing parenting training to their parents and guardians to provide a social safety net and to support them through the traumatic experiences and facilitating "boot camps" for the children and their parents to provide them with life skills necessary to navigate the challenges of adolescence.

\subsection{Challenges Faced in Intervening for Child Neglect}

The interview further revealed that Childline Kenya faces a myriad of challenges in their quest to intervene in child abuse and neglect cases. The challenges they face include iinsufficient information from the callers which makes it difficult to carry out an effective case management plan, the more information there is about the caller, the better the plan made as well as the interventions offered. Another problem faced by Childline Kenya is underfunding of the Department of Children Services, which is the umbrella body for Childline Kenya, this makes responding to cases of child abuse and neglect very difficult. Further, management of child abuse and neglect cases is hampered by language barriers. Most of the time, as indicated by the counselors, the children and caregivers calling speak different languages hence translators have to be used. Use of translators would mean confidentiality matters arise. It may take a while to get translators to respond to the case hence delay in getting help to the child.

The findings from the interviews also revealed that the callers may call once, report the case of child abuse and disappear. They become unavailable for further follow up. This therefore poses the challenge of knowing there is a child who was abused out there, yet you cannot reach them. Childline Kenya would definitely pursue the case to the end, but with unavailability of the callers for further follow up may bring the interventional measures to an end without ensuring the child is now safe.

It also emerged that some of child abuse and neglect cases require the inter- 
vention of the judicial system in order to ensure justice is served to the abused child as well as ensure their protection. The counselors reported during the interviews that judicial system in Kenya is very slow. Cases can take too long to be concluded hence the child suffers stress, anxiety and exhaustion as they wait for justice. Sometimes the delay in resolving the child matters eventually makes the child feel there is nothing much that can be done about my problems hence no need to ever report any other form of abuse.

\section{Discussions}

Child neglect is likely to cause great risk in children's lives. The findings from this study indicate that between 2016-2018, a total of 994 child neglect cases were reported in Kenya through the Childline Kenya helpline "116". These findings indicate that a significant number of children in Kenya are going through the abuse of child neglect. This findings are in line with the findings of Taylor \& Daniel (2005) who reported that in a study done by Straus and Kantor in 2003 on child neglect in a large cross national study covering over 5000 students in 14 nations, the number of respondents in the study who reported childhood experiences of one form of neglect varied from $20 \%$ to $95 \%$ while those reporting three or more forms of neglect varied from $3 \%$ to $36 \%$. In USA, Wilderman, Emmanuel, Waldefogel, \& Lee (2014) estimated that the lifetime child maltreatment including child neglect as $12.5 \%$ by the age 18 years. Other studies in the USA by Hyunil \& Wilderman (2017) indicate the cumulative risk through age 17 years was $25.2 \%$ for neglect from a child files cases for the period between 2003-2014.

Recent studies indicate increase in child neglect cases. These studies agree with the findings from Childline Kenya's helpline calls which indicate that reported child neglect cases in Kenya increased from 32.5\% (324) in 2016 to 38.4\% (382) in 2017. Administration for Children and Families Report (2018) in USA show that children who received child protective services investigation or alternative response increased by $8.4 \%(3,261,000)$ to $2018(3,534,000)$. In fact, those confirmed as having been maltreated increased in 2014 from $(675,000)$ to 2018 $(678,000)$, an increase of $0.4 \%$. It is startling to note that the report indicates that more than four-fifths of the victims of maltreatment suffer from one single form maltreatment, child neglect. The data indicates that $60.8 \%$ of the victims are neglected only, $10.7 \%$ are physically abused only and $7 \%$ sexually abused only. More than $15 \%$ are victims of two or more abuse types. Another study reported by Wilkinson \& Bowyer (2017), 21.9\% of children reported that they had been neglected by their parents. In Canada, a national study of cases reported to child welfare services found that, among the substantiated cases of neglect, $19 \%$ involved physical neglect, $12 \%$ abandonment, $11 \%$ educational neglect, and $48 \%$ physical harm resulting from a parent's failure to provide adequate supervision.

The findings of this study indicate a slight drop in reported cases of child neglect in Kenya, 28.9\% (288) in 2018. Although this is a slight drop, it is significant and worth appreciating the efforts that could have led to the drop for sustaina- 
bility sake. This drop is supported by the Administration for Children and Families Report (2019) which indicates that reported cases of maltreatment reduced in 2019 after a steady five year rise. The drop in child neglect cases observed in 2018 in Kenya may be attributed to either the adherence to the child protective measures that have been instituted. Conversely, it could also be that abused or neglected children are not calling to report abuse and neglect due to a lack of access to phones to call or ignorance on the existence of the helpline to report abuse and neglect. Hence, what appears as a drop in child neglect cases in 2018 may be due to non-reporting.

The findings of the study between 2016 and 2018 clearly show that child neglect is worse for the younger children compared to older ones. Cumulatively, across the three years under study, 32.4\% (323) of children aged 0 - 5 years experienced neglect while 29.5\% (294) aged 6 - 10 years also went through the same experience. Conversely, amongst the older children, only $26.2 \%$ (261) of children aged 11 - 15 years and 11.6\% (116) aged between $16-17$ years experienced neglect. The cases of neglect reported amongst the younger children are almost three times that of the older children hence the need to be keener in the protection of the very young children in our communities. It is therefore apparent that younger children experience child neglect more than the older children. These findings agree with the studies done by Wilkinson \& Bowyer (2017) which indicated that babies and younger children are mainly susceptible and reliant on parents and caregivers, which makes them more delicate and places them at greater risk of abuse and neglect and that adolescents are also vulnerable. Egry (2015) cites the work of Curitiba done in 2013 that illustrates that in a longitudinal study done between 2004 and 2012, children under the age of ten represents more than half the reports of neglect in the study period.

In terms of gender, findings of this study showed that both males and females experienced child neglect. However, the findings further show that between 2016 and 2018, more male children experienced neglect compared to females. Precisely, $51.8 \%$ (515) male children experienced neglect as opposed to $48.1 \%$ (479) females. These findings are similar to the findings of a study done in Brazil that showed that more boys suffered neglect compared to the girls (Egry, 2015). It is possible that the boys are experiencing more neglect than the girls due to cultural beliefs and practices. Garcia \& Guzman (2017) explained that boys are socialized to be serious and stern and that to show warmth and sensitivity is a sign of weakness. Unfortunately, some of these expectations turn into a form of abuse as the boys are not always able to take care of themselves.

\section{Recommendations}

Out of the findings of the study, the following recommendations are made towards the protection of children across the world. First, there is need to set up more child abuse and neglect reporting systems to complement efforts by helpline services. There are many cases of child abuse and neglect cases that go un- 
reported. The result of unreported cases implies that children continue suffering without any help resulting in psychological, social, physical harm to the child. In extreme cases, some of the children may die.

The statistics revealed in this study as well as the reviewed literature depict increasing child neglect cases globally which call for more robust measures to address child abuse and neglect cases. Well thought out plans and strategies should be put in place, implemented and monitored for effectiveness. This is an essential need across the world. Child protection measures that work and followed should be embraced globally for the best interest of the child.

The study found that both males and females experience neglect with the males experience slightly higher rates. There is therefore a need for more studies with larger samples to establish the extent of neglect based on gender. Further, there is need for more studies to establish the place of culture in differential treatment of children based on cultural beliefs and practices that are likely to contribute to abuse and neglect.

The study also established that younger children face neglect much more than older children hence a need for the establishment of more robust measures to ensure that all children are safe but pay special attention to the very young and vulnerable children. The younger children may not be in a position to verbalize or articulate what they go through as a result of neglect and abuse. This therefore calls for deliberate measures that put into consideration the needs of the very young and vulnerable children.

It has emerged that some cases of child abuse and neglect have gone unreported for a variety of reasons including a lack of knowledge on how and where to report abuse and neglect. Civic education and awareness creation on how and where to report will help enhance prevention of child abuse and neglect as well as enhance the protection of children. It is essential that civic education is spread across all nations, continents, rural and urban regions for information to reach all corners for the safety and protection of all children.

\section{Conclusion}

The study examined the prevalence of child neglect cases reported in Kenya, the nature and trends of child abuse reported in Kenya based on number of cases reported, the ages, gender and other emerging patterns in child neglect in 2016, 2017 and 2018. The study revealed that there was a high prevalence of reported child neglect cases in Kenya, that there was an increase in child neglect cases reported in 2016 and 2017, with a slight drop in 2018. It also emerged that both males and females experienced child neglect, but more cases were reported among the males than females. The study also outlined the challenges faced in intervening for child neglect but also highlights the intervention measures used by Childline Kenya.

Children are a treasure to its nations and deliberate efforts need to be put in place to ensure healthy development physically, cognitively, psychologically, 
emotionally and in all other dimensions of life. Child neglect is happening in many nations of the world, in fact many nations are reporting an increase in investigations and alternative responses to do with children, hence a need to pay more attention to child related problems. A multi-agency approach that is properly coordinated is likely to assist in the prevention of child abuse and neglect as well as in enhanced child protection mechanisms.

\section{Conflicts of Interest}

The author declares no conflicts of interest regarding the publication of this paper.

\section{References}

Administration for Children and Families (2018). Child Maltreatment Report. Washington DC: US Department of Health and Human Services.

Administration for Children and Families (2019). Child Maltreatment Report. Washington DC: US Department of Health and Human Services.

Badoe, E. (2017). A Critical Review of Child Abuse and Its Management in Africa. African Journal of Emergency Medicine, 7, S32-S35.

https://doi.org/10.1016/j.afjem.2017.09.002

Child Welfare Information Gateway (2019). Long Term Consequences of Child Abuse and Neglect. Washington DC: US Department of Health and Human Services, Administration for Children and Families Children's Bureau.

Childline Kenya (2009). Breaking the Silence: The Journey of 116-The Children's Helpline. Nairobi: Clarity Publications.

Deb, S. (2018). An Empirical Investigation into Child Abuse and Neglect in India: Burden Impact and Protective Measures. Singapore: Springer. https://doi.org/10.1007/978-981-10-7452-3

Depanfilis, D., \& Dubowitz, H. (2005). Family Connections: A Program for Preventing Child Neglect. Sage Journals: Child Maltreatment, 10, 108-123. https://doi.org/10.1177/1077559505275252

Egry, E. Y. (2015). Understanding Child Neglect in a Gender Context: A Study Performed in a Brazilian City. Sao Paulo: Creative Commons. https://doi.org/10.1590/S0080-623420150000400004

Garcia, A., \& Guzman, M. T. (2017). The Sage Encyclopedia of Psychology and Gender. Thousand Oaks, CA: Sage Publications.

Gilbert, R., Wisdom, C., Browne, K., Ferguson, D., Webb, E., \& Janson, S. (2009). Burden and Consequences of Child Maltreatment in Low Income Countries. The Lancet, 373, 68-81. https://doi.org/10.1016/S0140-6736(08)61706-7

Gultekin, G., \& Canturk, G. (2004). Emotional Abuse Behaviors of Adults. Journal of Forensic Psychiatry, 1, 13-18.

Hyunil, K., \& Wilderman, C. (2017). Lifetime Prevalence Investigating Child Maltreatment among US Children. AJPH Research, 107, 274-280. https://doi.org/10.2105/AJPH.2016.303545

Kothari, C. R. (2014). Research Methodology: Methods and Techniques (3rd ed.). New Delhi: New Age International (P) Limited.

Krug, E. G., Dahlberg, L. L., Mercy, J. A., Zwi, A. B., \& Lozano, R. (1996). World Health 
Report on Violence and Health. Geneva: WHO.

Moglia, P. (2015). Emotional Abuse. In Psychology \& Behavioral Health (pp. 647-650). Armenia, NY: Salem Press.

Ringui, J. (2012). A Survey of Factors Determining Development of Corporate Bonds Market in Kenya. Unpublished Master's Thesis, Nairobi: University of Nairobi.

Ruto, S. (2015). A Study of Child Abuse in Kenya. Kenya Catholic Secretariat of Religious Education.

Stoltenborgh, M., Bakersmans-Kranenburg, M., \& Ijzendoom, V. (2013). The Neglect of Child Neglect: A Meta-Analytic View Review of the Prevalence of Neglect. Social Psychiatry and Psychiatric Epidemiology, 48, 345-355.

https://doi.org/10.1007/s00127-012-0549-y

Taner, Y., \& Gokler, B. (2004). Child Neglect and Abuse: Psychiatric Sides. Hacettepe Medical Journal, 35, 82-86.

Taylor, J., \& Daniel, B. (2005). Child Neglect: Practice Issues for Health and Social Care. London: Jessica Kingsley Publishers.

Wilderman, C., Emmanuel, N., Waldefogel, J., \& Lee, H. (2014). The Prevalence of Confirmed Maltreatment among US Children. JAMA Pediatrics, 168, 706-713.

https://doi.org/10.1001/jamapediatrics.2014.410

Wilkinson, J., \& Bowyer, S. (2017). The Impact of Abuse and Neglect on Children; and Comparison of Different Placement Options. Department of Education. Research in Practice.

WHO (2020). Child Maltreatment.

https://www.who.int/news-room/fact-sheets/detail/child-maltreatment 